This item was submitted to Loughborough's Research Repository by the author.

Items in Figshare are protected by copyright, with all rights reserved, unless otherwise indicated.

\title{
Demand response in smart grid - A systematic mapping study
}

PLEASE CITE THE PUBLISHED VERSION

https://doi.org/10.1109/spies48661.2020.9243107

PUBLISHER

IEEE

VERSION

AM (Accepted Manuscript)

\section{PUBLISHER STATEMENT}

Personal use of this material is permitted. Permission from IEEE must be obtained for all other uses, in any current or future media, including reprinting/republishing this material for advertising or promotional purposes, creating new collective works, for resale or redistribution to servers or lists, or reuse of any copyrighted component of this work in other works.

\section{LICENCE}

All Rights Reserved

\section{REPOSITORY RECORD}

Siddiquee, SM Shahnewaz, Bianca Howard, Dominic TJ O'Sullivan, and Ken Bruton. 2020. "Demand Response in Smart Grid - A Systematic Mapping Study". Loughborough University. https://hdl.handle.net/2134/13365347.v1. 


\section{Demand Response in Smart Grid - A Systematic Mapping Study}

\author{
S M Shahnewaz Siddiquee \\ Intelligent Efficiency Research Group \\ (IERG) \\ University College Cork \\ College Rd, Cork, Ireland \\ 119222676@umail.ucc.ie \\ Dominic T. J. O'Sullivan \\ Intelligent Efficiency Research Group \\ (IERG) \\ University College Cork \\ College Rd, Cork, Ireland
}

\author{
Bianca Howard \\ School of Architecture, Building and \\ Civil Engineering \\ Loughborough University \\ United Kingdom
}

\author{
Ken Bruton \\ Intelligent Efficiency Research Group \\ (IERG) \\ University College Cork \\ College Rd, Cork, Ireland
}

\begin{abstract}
Growing demand for electricity and the innovations in smart grid technologies is providing new opportunities for intelligent electrical demand control in the form of Demand Response (DR). In this paper, we present a comprehensive review of demand response by conducting a systematic mapping of the field to evaluate the current research trends, knowledge gaps, and the scope of future research of DR in the smart grid context. Bibliometric analysis has been done to map the intermittent research themes under the demand response domain by exploiting the co-relationships in the metadata originated from the SCOPUS database. Thorough content analysis has also been performed and six emerging research themes have been identified along with key research questions commonly addressed to devise future research directions.
\end{abstract}

Keywords-Demand Response, Smart Grid, Systematic Mapping, Bibliometric Analysis

\section{INTRODUCTION}

In recent years, the electricity grid has been undergoing under a rapid change because of energy conservation as well as environmental sustainability. Aging infrastructure and demand for improving operational efficiency call for a reliable grid. However owing to the rapid proliferation of renewable energy sources, the grid and grid operators are facing operational challenges to meet operational reliability [1].

Furthermore, governments are also imposing grid operators with strict policies and regulations to cut carbon emissions and integrate more renewable generations. Distributed energy sources (DERs) are highly intermittent which can lead to additional ramping in the grid hence compromising the grid stability.

Demand Response (DR) refers to "the change in electric usage by end-use customers from their normal consumption patterns in response to changes in the price of electricity over time or to incentive payments designed to induce lower electricity use at times of high wholesale market price or when the system reliability is jeopardized"[2]. DR can help in accommodating intermittent renewable energy generation by incorporating demand-side flexibility. Hence it has drawn compelling attention from both academia and industry in recent years which lead to the rapid growth of research on demand response including a considerable amount of scientific literature i.e. journal articles, conference preceding, and books. This considerable volume of literature is making it challenging and time-consuming for researchers and DR practitioners to get a synoptic and structured overview of the relevant as well as up to date information. To date, several review papers have been published covering the general concept of DR and recent advances in academia as well as industrial research on DR [3]-[5].

In this paper, we are aiming to provide a comprehensive and structured overview of the DR domain by systematic mapping of the domain. In this regard, a Bibliometric analysis has been done followed by a content analysis of the identified research themes and the broad domain. The key contribution of the can be summarized as,

The Bibliometric analysis provides an in-depth visualization and ranking of the literature under review, associated keyword trends, a conceptual map which in turn provides a swift overview of the DR research.

Furthermore, a detailed content analysis of the selected scientific literature gives us the current research questions addressed by the top researchers, state of the art methods to solve those problems and also a good understanding to provide future research direction.

The organization of the rest of the papers is as follows; Section II provides an overview of the methodology of systematic mapping followed by Section III which includes the bibliometric analysis results. Section IV contains the analysis of the demand response research themes formulated from content analysis and Section $\mathrm{V}$ includes concluding remarks by outlining the future research direction of DR.

\section{Methodology}

\section{A. Systematic Mapping Framework}

Fig 1. shows the comprehensive framework of the systematic mapping study. Under the framework, an initial repository has been created containing the metadata of the relevant literature from a reliable database (SCOPUS). The initial search results have been filtered accordingly to exclude any irrelevant data or literature which does not fall under the scope of the study. Bibliometric analysis has been carried out 


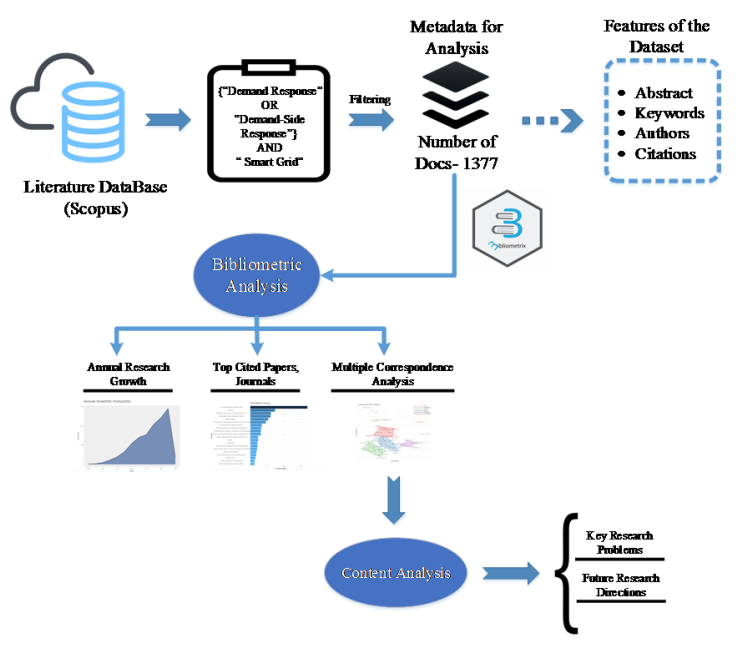

Fig. 1. Systematic Mapping Framework

on the refined metadata. The bibliometric analysis comprised a qualitative and quantitative analysis of bibliometric data providing insight into the research domain by hightlighting the patterns of publications, associated institutions as well as journals[6].

An in-depth content analysis based on the research themes identified from the bibliometric analysis provided the latest advancement, current gaps in each of the research sub-themes which in turn give an indication of future development on the particular topic.

\section{B. Data and Tools}

The datum was retrieved from the SCOPUS database, one of the most reliable scientific citation index databases in the research community. The search terms were combined with different keywords that commonly represents the DR domain. Initial search results showed publications dated by in the $90 \mathrm{~s}$ with the fundamental concept of DR. For the relevancy of the latest research activity, a period between "2008-2020" has been considered while searching for relevant data.

TABLE I. SEARCH STRING TERMS

\begin{tabular}{c|c|c}
\hline \hline SEARCH TERMS & $\begin{array}{c}\text { SEARCH } \\
\text { AREA }\end{array}$ & $\begin{array}{c}\text { FILTRATION } \\
\text { CRITERIA }\end{array}$ \\
\hline $\begin{array}{c}\text { \{"Demand Response } \\
\text { "OR "Demand Side } \\
\text { Response" } \\
\text { "Smant Grid" }\end{array}$ & All Fields & Include - Journal Article \\
& & Limit to (2020-2008) \\
\hline \hline
\end{tabular}

Table I shows the related search term and filtration criteria on the SCOPUS database. The initial search result came with 5534 articles which were numbered down to 1377 after applying the filtration criteria. This metadata has been used to carry out the bibliometric analysis.

\section{BIBLIOMETRIC ANALYSIS}

\section{A. Publication Trend and Research Growth :}

The metadata from SCOPUS includes information such as publication year, authors, titles, abstracts, and references which can be effectively used to carry out the bibliometric analysis and information visualization. "Bibliometrix" - an R based tool[7] is used to analyze and visualize the corelationships in the metadata.
One of the most important indications of the development of the research field is the number of peer-reviewed

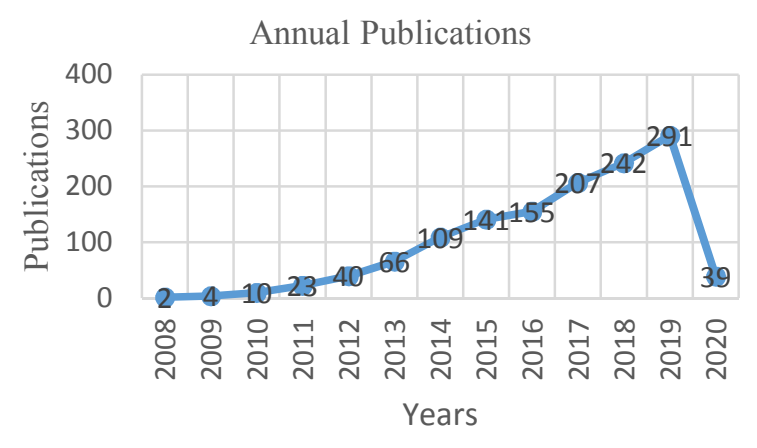

Fig. 2. Annual research growth based on SCOPUS database

publications each year. Fig 2 shows annual research growth by outlining the total number of publications each year.

The cumulative progression of fig 2 depicts the steady increase of peer-reviewed scientific literature from 2008-2020 which strongly suggests the growth of demand response related research. The year 2020 only included the articles published until January $26^{\text {th }}$. It could be concluded that the quantity of the scientific literature on demand response will increase at a significant number in the coming years.

\section{B. Top Source Journal :}

Top source journals that are publishing most frequently in the areas of Demand Response have been extracted and categorized based on the total number of publications (NP) and the total number of citations (NC). This categorization will give an impression of influential Journals to the researchers for monitoring the progress of the discipline. Table II categorized the top 5 journals from the SCOPUS metadata where the IEEE transaction on Smart Grid has the highest number of published literature in terms of NP as well as NC.

TABLE II. Top Most Contributing Source Title

\begin{tabular}{cccc}
\hline \hline JOURNAL & NP & NC & PUBLISHER \\
\hline IEEE Trans On Smart Grid & 169 & 7560 & IEEE \\
Energies & 73 & 399 & MDPI \\
$\begin{array}{c}\text { Dianwang Jishu/Power System } \\
\text { Technology }\end{array}$ & 61 & 564 & $\begin{array}{c}\text { Power System } \\
\text { Technology } \\
\text { Press }\end{array}$ \\
$\begin{array}{c}\text { IEEE Transaction On Power } \\
\text { System }\end{array}$ & 60 & 2375 & IEEE \\
Applied Energy & 53 & 993 & Elsevier \\
\hline \hline
\end{tabular}

\section{Country Wise Analysis}

In this section, the top most productive countries in terms of the number of publications are presented. The number of publications from a country reflects the attention and the overall research strengths of this country in the related field of research. Table III shows the order of the countries sorted by NP, also taking into account the NC. A total of 525 articles has been published from 1377 articles where the corresponding author is affiliated to the countries from Table 
III which accounts for $38 \%$ of the total publications. China tops the table with 228 articles followed by the USA with 111 publications.

TABLE III. Top Most Productive Countries

\begin{tabular}{ccc}
\hline \hline COUNTRIES & NP & NC \\
\hline China & 288 & 2969 \\
USA & 111 & 5726 \\
South Korea & 54 & 1441 \\
United Kingdom & 38 & 690 \\
Japan & 34 & 771 \\
\hline \hline
\end{tabular}

\section{Institutional Performance}

Table IV illustrates the top-performing institutions in terms of the number of publications. China outperformed the rest of the world with 5 institutions in the top 10 most contributing institutions where North China Electric Power University secures the top position with 99 publications.

TABLE IV. Top Most Productive Institutions

\begin{tabular}{cll}
\hline \hline INSTITUTIONS & COUNTRY & NP \\
\hline North China Electric Power University & China & 99 \\
China Electric Power Research Institute & China & 61 \\
South East University & China & 51 \\
Tianjin University & China & 35 \\
Shanghai Jiao Tong University & China & 27 \\
\hline \hline
\end{tabular}

\section{E. Most Cited Articles:}

Table V lists the highly influential papers based on the number of citations each paper got throughout the analyzed period. The main focus of the papers is on a conceptual review of DR as well as proposing optimization and control framework for cost minimization and energy saving.

TABLE V. Top Most Influential ARticle

\begin{tabular}{|c|c|c|c|c|}
\hline$\overline{~ A R T I C L E ~}$ & REF & $\overline{\mathrm{NC}}$ & $\overline{~ K E Y W O R D S ~}$ & בCONTRIBUTION \\
\hline $\begin{array}{l}\text { Palensky et } \\
\text { al, } 2011\end{array}$ & [8] & 1457 & $\begin{array}{c}\text { DSM, Energy } \\
\text { Efficiency, DR, } \\
\text { Load } \\
\text { Management, } \\
\text { Peak Shaving }\end{array}$ & Review \\
\hline $\begin{array}{l}\text { Ipakachi et } \\
\text { al, } 2009\end{array}$ & {$[1]$} & 1171 & $\begin{array}{l}\text { DER, DR, HEV, } \\
\text { Load Shaping, } \\
\text { Smart Grid }\end{array}$ & Review \\
\hline $\begin{array}{l}\text { LU N et al, } \\
2012\end{array}$ & [9] & 370 & $\begin{array}{c}\text { Air Conditioning, } \\
\text { Ancillary } \\
\text { Service, HVAC, } \\
\text { Direct Load } \\
\text { Control, DR }\end{array}$ & $\begin{array}{l}\text { Framework, } \\
\text { Optimization }\end{array}$ \\
\hline $\begin{array}{l}\text { Fan } Z \text { et al, } \\
2013\end{array}$ & {$[10]$} & 327 & $\begin{array}{c}\text { Smart Grid, } \\
\text { Communication }\end{array}$ & Review \\
\hline $\begin{array}{l}\text { Mathieu J } \\
\text { L et } \\
\text { al,2010 }\end{array}$ & {$[11]$} & 299 & $\begin{array}{l}\text { DR, Predictive } \\
\text { Control, State } \\
\text { Estimation, }\end{array}$ & Control Framework \\
\hline
\end{tabular}

\begin{tabular}{|c|c|c|c|c|}
\hline & & & $\begin{array}{c}\text { Thermal load } \\
\text { Control }\end{array}$ & \\
\hline $\begin{array}{l}\text { TSUI KM } \\
\text { et al,2017 }\end{array}$ & {$[12]$} & 238 & $\begin{array}{l}\text { DR, Energy } \\
\text { Consumption } \\
\text { Scheduling, } \\
\text { Smart Home }\end{array}$ & Optimization \\
\hline $\begin{array}{l}\text { Medina } J \text { et } \\
\text { al,2010 }\end{array}$ & [13] & 202 & $\begin{array}{l}\text { DR, Distributed } \\
\text { DR Operations, } \\
\text { DR management }\end{array}$ & Review \\
\hline $\begin{array}{l}\text { Kang J et } \\
\text { al,2014 }\end{array}$ & [14] & 190 & $\begin{array}{c}\text { Energy Internet, } \\
\text { PHEV, } \\
\text { Blockchain }\end{array}$ & Framework \\
\hline $\begin{array}{l}\text { Chai B et } \\
\text { al,2014 }\end{array}$ & {$[15]$} & 190 & $\begin{array}{l}\text { DR, Energy } \\
\text { Pricing }\end{array}$ & $\begin{array}{l}\text { Peak Load Control } \\
\text { framework }\end{array}$ \\
\hline $\begin{array}{l}\text { Bahrami S } \\
\text { et al,2016 }\end{array}$ & {$[16]$} & 167 & $\begin{array}{c}\text { DR, Smart } \\
\text { Energy Hub }\end{array}$ & Framework \\
\hline
\end{tabular}

\section{DEMAND RESPONSE: ANALYSIS OF THE RESEARCH THEMES}

Keywords are generally used to emphasize the research theme as well as the content of the publications. In this study, the keywords associated with each paper have been utilized to identify a common research theme to create a conceptual map of Demand Response research. Using the bibliometrix tool, a multiple corresponding analysis (MCA) has been performed to draw the conceptual structure using a word co-occurrence network to map and cluster keyword terms that are frequently occurring in a bibliographic collection Fig 3 illustrates the conceptual map and keyword cluster from MCA. The figure can be interpreted based on the relative position of the points and their distribution along the dimensions; as words are more similar in distribution, the closer they represent in the figure[7].

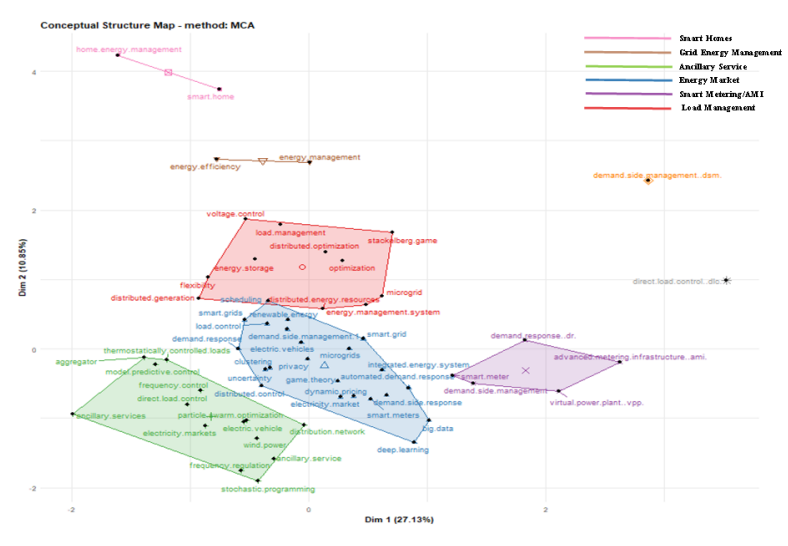

Fig. 3. Conceptual Structure from multiple corresponding analysis

In fig 3, each cluster essentially represents a group of keywords that expresses a common research theme. From the analysis, six key research theme have been identified and an elaborate content analysis based on selected literature has been carried out where frequent research questions addressed by the research community on identified themes have been described and grouped. Table VI provides an overview of each of the research domain with identified research questions. 
TABLE VI. OVERVIEW OF RESEARCH THEMES IN DEMAND RESPONSE

\begin{tabular}{|c|c|c|c|}
\hline $\begin{array}{l}\text { RESEARCH } \\
\text { THEME }\end{array}$ & CONTENT & RESEARCH QUESTIONS & REFERENCES \\
\hline Smart Homes & $\begin{array}{l}\text { Residential DR, } \\
\text { Commercial DR, } \\
\text { Appliance Scheduling }\end{array}$ & $\begin{array}{l}\text { RQ1. Which type of residential equipment is suitable for DR } \\
\text { and How long it can participate in DR without compromising } \\
\text { user comfort? } \\
\text { RQ2. What are the key factors in pricing schemes that provide } \\
\text { the maximum user participation in DR.? } \\
\text { RQ3 What framework works best in optimizing the load hence } \\
\text { maximizing energy saving in DR? } \\
\text { RQ } 4 \text { How to deal with the uncertainties in DR? }\end{array}$ & $\begin{array}{l}{[17][18][19][20][21][22][23][24][25][26]} \\
{[27]}\end{array}$ \\
\hline $\begin{array}{l}\text { Grid Energy } \\
\text { Management }\end{array}$ & $\begin{array}{l}\text { DER Integration, } \\
\text { Energy Management in } \\
\text { Micro-grid }\end{array}$ & $\begin{array}{l}\text { RQ5 How to accurately model DR participating assets? } \\
\text { RQ6. What is the impact of the DR Framework on grid-level } \\
\text { energy management considering maximum DER Integration } \\
\text { and uncertainties? }\end{array}$ & {$[28][29][30][31][32][33][34][35][36]$} \\
\hline $\begin{array}{l}\text { Ancillary } \\
\text { Services }\end{array}$ & $\begin{array}{l}\text { Frequency Control, } \\
\text { Peak-load control } \\
\text { Voltage Regulation }\end{array}$ & $\begin{array}{l}\text { RQ7. What is the impact of load characteristics in system } \\
\text { operational parameters ( frequency, voltage)? }\end{array}$ & {$[37][38][39]$} \\
\hline $\begin{array}{l}\text { Load } \\
\text { Management }\end{array}$ & $\begin{array}{l}\text { Controllable Thermal } \\
\text { Load, Electric Vehicles } \\
(\mathrm{EV})\end{array}$ & $\begin{array}{l}\text { RQ8 How to aggregate different types of (controllable Flexible } \\
\text { thermal) loads and utilize different control methods to perform } \\
\text { DR associated services? }\end{array}$ & {$[40][41][42][42]$} \\
\hline $\begin{array}{l}\text { Energy } \\
\text { Market }\end{array}$ & $\begin{array}{l}\text { Market Model } \\
\text { Incentive Planning }\end{array}$ & $\begin{array}{l}\text { RQ9. What market structure/scheme works best in terms of DR } \\
\text { profit maximization? } \\
\text { RQ10 How to incorporate the uncertainties in Energy Market } \\
\text { Framework? }\end{array}$ & {$[43][44][45][46][47][48][49][50]$} \\
\hline $\begin{array}{l}\text { Smart } \\
\text { Metering } \\
\text { /AMI }\end{array}$ & $\begin{array}{l}\text { Non-Intrusive Load } \\
\text { Monitoring (NILM); } \\
\text { Energy Meter Data } \\
\text { Analysis }\end{array}$ & $\begin{array}{l}\text { RQ11. How to model the individual pattern of device-level } \\
\text { electrical load in DR application? } \\
\text { RQ12. How to identify different assets/ appliances in } \\
\text { Residential / Commercial DR Context? } \\
\text { RQ13. What are the key features in Smart Meter data that help } \\
\text { facilitate decision making in DR? } \\
\text { RQ14. How to make the system more secure; Detection of } \\
\text { Cyber Attack? }\end{array}$ & {$[51][52][53][54][55][56]$} \\
\hline
\end{tabular}

\section{A. Smart Homes:}

Among the research themes, articles have been published under Smart Homes where an emphasis has been given on the identification of suitable assets that can participate in a demand response program. Different optimization frameworks that considered the key optimization parameters such as cost, energy efficiency, user comfort are also been addressed. Pricing schemes remain a key challenge to identify the user's willingness to participate in DR programs. Alternatively, the estimation of uncertainties in electrical load estimation, as well as the frameworks to include the uncertainty measurement, are getting significant attention.

\section{B. Grid Energy Management :}

Different DR control frameworks on grid-level energy management with distributed energy resources have been investigated to assess impact in terms of maximizing DER integration to the grid. Demand response facilitates DER integration by incorporating different resources (thermal loads, EVs, Energy Storage) and utilizing their flexible load changing capacity. However accurate mathematical modeling of these resources is very important to fully harness their capacity and integrate them into a DR framework.

\section{Ancilliary Services :}

Several literatures were also focused on utilizing DR for ancillary services. As the penetration of intermittent resources is increasing continuously, hence the grid stability issues such as frequency and voltage regulations are getting attention under the DR paradigm. The effect of system parameters due to external disturbances, for example, large generation drop or large load drops are being studied while the impact of the load characteristics on system parameters has also been researched extensively in recent days.

\section{Load Management :}

The increasing number of thermal loads, as well as EVs, brings massive challenges to the traditional grid. However, some loads such as EVs can also be utilized to inject the electrical power back to the grid. This provides a great opportunity to achieve active demand response and provide associated services to facilitate grid stability in the presence of intermittent resources. But how to aggregate different types of loads to participate in the DR framework, also coordinated control of these loads remains an important research question that is being addressed under the direct load management research theme. 


\section{E. Energy Market :}

There have been some extensive studies on the market behavior of demand response resources. Different market structures and strategies remain the primary focus of many literatures. The lack of a market mechanism in the current market structure (Day-ahead/Real-Time) remains a great barrier for demand response in most countries. Without an accurate market mechanism and demand response model, it is hardly possible to estimate the true impact of the demand response market, hence there will be a significant change in financial outcome for the consumers which has been estimated from the existing model.

\section{F. Smart Metering :}

The penetration of advanced metering infrastructure enables consumers to participate more in DR programs. Since the introduction of market deregulation and market-driven pricing, utilities have been searching to equalize consumption with generation. Smart meters are providing site-specific information which helps to make decisions in response to changing prices for electricity according to the time of the day and season. Hence feature analysis of smart meter data has been getting significant research attention. Alternatively, smart technologies such as Non-intrusive load monitoring (NILM) are getting popular for device-level detection. As more appliances are now becoming intelligent i.e. IoT enabled, it opens up a new dimension where research has been done on identifying an individual device status to facilitate cost-effective scheduling under the DR program.

\section{CONCLUSION}

In this paper, a comprehensive mapping of demand-side response has been carried out under the smart grid paradigm. Demand response has shown to be efficient in mitigating many grid operational challenges. Though there have been numerous research outcomes on demand response, there are still some challenges and research questions that need further attention,

- From the study, it is evident that a lot of research has been done in both residential and commercial DR context. However, there are very few cases of DR application in an industrial context. As industries also employ flexible controllable load, evaluation of DR potential in an industrial context will prove valuable to exploit in the long run.

- Introduction of EVs, Energy storage will create new opportunities for residential and commercial level DR. Therefore more research to facilitate these assets in DR will be required.

- User comfort and pricing remains a key barrier for DR participation by the consumers. Introducing new strategies and control frameworks that attracts the consumers to participate in DR can be considered as an important research challenge.

- $\quad$ Effect of DR schemes in the electricity market with different levels of competition is recommended for further investigation.

- Proper mathematical modeling of assets and formulating the optimization problem with more detailed parameters for DR programs are required in the future.
- As more advanced computing technologies are being involved, analysis of higher resolution smart meter data as well as interpreting the patterns will get more attention in the future.

- Responding to cyber threats remains a big question, as more and more smart meters are being deployed proper data encryption and introducing more security features remains a big challenge that needs to be addressed.

\section{ACKNOWLEDGEMENT}

This research was part-funded by Science Foundation Ireland (SFI) through MaREI, the SFI Research Centre for Energy, Climate, and Marine and specially the Centre for Doctoral Training in Energy Resilience and the Built Environment (ERBE) (grant no: 12/RC/2302_P2), with supporting funding obtained from UK Engineering and Physical Sciences Research Council (EPSRC) (grant EP/S021671/1) and FlexTECC: Flexible Timing of Energy Consumption in Communities Innovation Fellowship (grant $\mathrm{EP} / \mathrm{S} 001670 / 1)$.

\section{REFERENCES}

[1] A. Ipakchi and F. Albuyeh, "Grid of the future," IEEE Power Energy Mag., vol. 7, no. 2, pp. 52-62, 2009.

[2] S. Chen and C.-C. Liu, "From demand response to transactive energy: state of the art," J. Mod. Power Syst. Clean Energy, vol. 5, no. 1, pp. 10-19, 2017.

[3] V. S. K. M. Balijepalli, V. Pradhan, S. A. Khaparde, and R. M. Shereef, "Review of demand response under smart grid paradigm," 2011 IEEE PES Int. Conf. Innov. Smart Grid Technol. ISGT India 2011, pp. 236-243, 2011, doi: 10.1109/ISET-India.2011.6145388.

[4] R. S. El Geneidy and B. Howard, "Review of techniques to enable community-scale demand response strategy design," uSim2018 Urban Energy Simul., 2018.

[5] J. Wang, H. Zhong, Z. Ma, Q. Xia, and C. Kang, "Review and prospect of integrated demand response in the multi-energy system," Appl. Energy, vol. 202, pp. 772-782, 2017.

[6] Y. M. Guo, Z. L. Huang, J. Guo, H. Li, X. R. Guo, and M. J. Nkeli, "Bibliometric analysis on smart cities research," Sustain., vol. 11, no. $13,2019$.

[7] M. Aria and C. Cuccurullo, "bibliometrix: An R-tool for comprehensive science mapping analysis," J. Informetr., vol. 11, no. 4, pp. 959-975, 2017.

[8] P. Palensky and D. Dietrich, "Demand side management: Demand response, intelligent energy systems, and smart loads," IEEE Trans. Ind. Informatics, vol. 7, no. 3, pp. 381-388, 2011.

[9] N. Lu, "An evaluation of the HVAC load potential for providing load balancing service," IEEE Trans. Smart Grid, vol. 3, no. 3, pp. 1263-1270, 2012.

[10] Z. Fan et al., "Smart grid communications: Overview of research challenges, solutions, and standardization activities," IEEE Commun. Surv. Tutorials, vol. 15, no. 1, pp. 21-38, 2013.

[11] J. L. Mathieu, P. N. Price, S. Kiliccote, and M. A. Piette, "Quantifying changes in building electricity use, with application to demand response," IEEE Trans. Smart Grid, vol. 2, no. 3, pp. 507-518, 2011.

[12] K. M. Tsui and S. C. Chan, "Demand response optimization for smart home scheduling under real-time pricing," IEEE Trans. Smart Grid, vol. 3, no. 4, pp. 1812-1821, 2012.

[13] J. Medina, N. Muller, and I. Roytelman, "Demand response and distribution grid operations: Opportunities and challenges," IEEE Trans. Smart Grid, vol. 1, no. 2, pp. 193-198, 2010.

[14] J. Kang, R. Yu, X. Huang, S. Maharjan, Y. Zhang, and E. Hossain, "Enabling Localized Peer-to-Peer Electricity Trading among Plugin Hybrid Electric Vehicles Using Consortium Blockchains," IEEE Trans. Ind. Informatics, vol. 13, no. 6, pp. 3154-3164, 2017.

[15] B. Chai, J. Chen, S. Member, Z. Yang, Y. Zhang, and S. Member, "Utility Companies : A Two-Level Game Approach," vol. 5, no. 2, pp. 722-731, 2014.

[16] S. Bahrami and A. Sheikhi, "From Demand Response in Smart Grid Toward Integrated Demand Response in Smart Energy Hub," 
IEEE Trans. Smart Grid, vol. 7, no. 2, pp. 650-658, 2016. R. D'hulst, W. Labeeuw, B. Beusen, S. Claessens, G. Deconinck, and K. Vanthournout, "Demand response flexibility and flexibility potential of residential smart appliances: Experiences from large pilot test in Belgium," Appl. Energy, vol. 155, pp. 79-90, 2015.

[18] C. B. A. Kobus, E. A. M. Klaassen, R. Mugge, and J. P. L. Schoormans, "A real-life assessment on the effect of smart appliances for shifting households' electricity demand," Appl. Energy, vol. 147, pp. 335-343, 2015.

[19] W. Labeeuw, J. Stragier, and G. Deconinck, "Potential of active demand reduction with residential wet appliances: A case study for Belgium," IEEE Trans. Smart Grid, vol. 6, no. 1, pp. 315-323, 2015.

[20] K. Ma, T. Yao, J. Yang, and X. Guan, "Residential power scheduling for demand response in smart grid," Int. J. Electr. Power Energy Syst., vol. 78, pp. 320-325, 2016, doi: 10.1016/j.ijepes.2015.11.099.

[21] K. X. Perez, M. Baldea, and T. F. Edgar, "Integrated HVAC management and optimal scheduling of smart appliances for community peak load reduction," Energy Build., vol. 123, pp. 34 40, 2016, doi: 10.1016/j.enbuild.2016.04.003.

[22] M. Pipattanasomporn, M. Kuzlu, S. Rahman, and Y. Teklu, "Load profiles of selected major household appliances and their demand response opportunities," IEEE Trans. Smart Grid, vol. 5, no. 2, pp. 742-750, 2014.

[23] S. Shao, M. Pipattanasomporn, and S. Rahman, "Development of physical-based demand response-enabled residential load models," IEEE Trans. Power Syst., vol. 28, no. 2, pp. 607-614, 2013.

[24] Z. Yu, L. Jia, M. C. Murphy-Hoye, A. Pratt, and L. Tong, "Modeling and stochastic control for home energy management," IEEE Trans. Smart Grid, vol. 4, no. 4, pp. 2244-2255, 2013.

[25] C. Bartusch, F. Wallin, M. Odlare, I. Vassileva, and L. Wester, "Introducing a demand-based electricity distribution tariff in the residential sector: Demand response and customer perception," Energy Policy, vol. 39, no. 9, pp. 5008-5025, 2011.

[26] S. Li, D. Zhang, A. B. Roget, and Z. O'Neill, "Integrating home energy simulation and dynamic electricity price for demand response study," IEEE Trans. Smart Grid, vol. 5, no. 2, pp. 779788, 2014.

[27] Q. Hu and F. Li, "Hardware design of smart home energy management system with dynamic price response," IEEE Trans. Smart Grid, vol. 4, no. 4, pp. 1878-1887, 2013.

[28] K. Balasubramaniam, P. Saraf, R. Hadidi, and E. B. Makram, "Energy management system for enhanced resiliency of microgrids during islanded operation," Electr. Power Syst. Res., vol. 137, pp. 133-141, 2016.

[29] B. V Solanki, A. Raghurajan, K. Bhattacharya, and C. A. Canizares, "Including Smart Loads for Optimal Demand Response in Integrated Energy Management Systems for Isolated Microgrids," IEEE Trans. Smart Grid, vol. 8, no. 4, pp. 1739$1748,2017$.

[30] G. Brusco, A. Burgio, D. Menniti, A. Pinnarelli, and N. Sorrentino, "Energy management system for an energy district with demand response availability," IEEE Trans. Smart Grid, vol. 5, no. 5, pp. 2385-2393, 2014.

[31] A. Bernstein, L. Reyes-Chamorro, J.-Y. Le Boudec, and M. Paolone, "A composable method for real-time control of active distribution networks with explicit power setpoints. Part I: Framework," Electr. Power Syst. Res., vol. 125, pp. 254-264, 2015.

[32] S. Baldi, A. Karagevrekis, I. T. Michailidis, and E. B. Kosmatopoulos, "Joint energy demand and thermal comfort optimization in photovoltaic-equipped interconnected microgrids," Energy Convers. Manag., vol. 101, pp. 352-363, 2015.

[33] M. Alipour, B. Mohammadi-Ivatloo, and K. Zare, "Stochastic Scheduling of Renewable and CHP-Based Microgrids," IEEE Trans. Ind. Informatics, vol. 11, no. 5, pp. 1049-1058, 2015.

[34] J. Aghaei, M. Barani, M. Shafie-Khah, A. A. Sanchez De La Nieta, and J. P. S. Catalao, "Risk-Constrained Offering Strategy for Aggregated Hybrid Power Plant Including Wind Power Producer and Demand Response Provider," IEEE Trans. Sustain. Energy, vol. 7, no. 2, pp. 513-525, 2016.

[35] Q. Wang, J. Wang, and Y. Guan, "Stochastic unit commitment with uncertain demand response," IEEE Trans. Power Syst., vol. 28, no. 1, pp. 562-563, 2013.
[36] J. Liu, H. Chen, W. Zhang, B. Yurkovich, and G. Rizzoni, "Energy Management Problems under Uncertainties for Grid-Connected Microgrids: A Chance Constrained Programming Approach," IEEE Trans. Smart Grid, vol. 8, no. 6, pp. 2585-2596, 2017.

[37] H. Huang and F. Li, "Sensitivity analysis of load-damping characteristic in power system frequency regulation," IEEE Trans. Power Syst., vol. 28, no. 2, pp. 1324-1335, 2013.

[38] P. Kadurek, J. F. G. Cobben, W. L. Kling, and P. F. Ribeiro, "Aiding power system support by means of voltage control with intelligent distribution substation," IEEE Trans. Smart Grid, vol. 5, no. 1, pp. 84-91, 2014.

[39] E. Vrettos and G. Andersson, "Scheduling and Provision of Secondary Frequency Reserves by Aggregations of Commercial Buildings," IEEE Trans. Sustain. Energy, vol. 7, no. 2, pp. 850864, 2016.

[40] N. Mahdavi, J. H. Braslavsky, M. M. Seron, and S. R. West, "Model Predictive Control of Distributed Air-Conditioning Loads to Compensate Fluctuations in Solar Power," IEEE Trans. Smart Grid, vol. 8, no. 6, pp. 3055-3065, 2017.

[41] J. L. Mathieu, S. Koch, and D. S. Callaway, "State estimation and control of electric loads to manage real-time energy imbalance," IEEE Trans. Power Syst., vol. 28, no. 1, pp. 430-440, 2013.

[42] F. Luo, Z. Y. Dong, K. Meng, J. Wen, H. Wang, and J. Zhao, “An Operational Planning Framework for Large-Scale Thermostatically Controlled Load Dispatch," IEEE Trans. Ind. Informatics, vol. 13, no. 1, pp. 217-227, 2017.

[43] N. Mahmoudi, M. Eghbal, and T. K. Saha, "Employing demand response in energy procurement plans of electricity retailers," Int. J. Electr. Power Energy Syst., vol. 63, pp. 455-460, 2014.

[44] S. Maharjan, Q. Zhu, Y. Zhang, S. Gjessing, and T. Başar, "Demand response management in the smart grid in a large population regime," IEEE Trans. Smart Grid, vol. 7, no. 1, pp. 189-199, 2016.

[45] N. Li, L. Chen, and M. A. Dahleh, "Demand Response Using Linear Supply Function Bidding," IEEE Trans. Smart Grid, vol. 6, no. 4, pp. 1827-1838, 2015.

[46] H. Li, X. Lin, H. Yang, X. Liang, R. Lu, and X. Shen, "EPPDR: An efficient privacy-preserving demand response scheme with adaptive key evolution in smart grid," IEEE Trans. Parallel Distrib. Syst., vol. 25, no. 8, pp. 2053-2064, 2014.

[47] H. S. V. S. K. Nunna and D. Srinivasan, "Multiagent-Based Transactive Energy Framework for Distribution Systems with Smart Microgrids," IEEE Trans. Ind. Informatics, vol. 13, no. 5, pp. 2241-2250, 2017.

[48] M. Kazemi, B. Mohammadi-Ivatloo, and M. Ehsan, "Risk-based bidding of large electric utilities using Information Gap Decision Theory considering demand response," Electr. Power Syst. Res., vol. 114, pp. 86-92, 2014.

[49] M. Kazemi, B. Mohammadi-Ivatloo, and M. Ehsan, "Riskconstrained strategic bidding of GenCos considering demand response," IEEE Trans. Power Syst., vol. 30, no. 1, pp. 376-384, 2015.

[50] D. T. Nguyen, M. Negnevitsky, and M. De Groot, "Market-based demand response scheduling in a deregulated environment," IEEE Trans. Smart Grid, vol. 4, no. 4, pp. 1948-1956, 2013.

[51] M. Dong, P. C. M. Meira, W. Xu, and W. Freitas, "An event window based load monitoring technique for smart meters," IEEE Trans. Smart Grid, vol. 3, no. 2, pp. 787-796, 2012.

[52] K. Gajowniczek and T. Zabkowski, "Data mining techniques for detecting household characteristics based on smart meter data," Energies, vol. 8, no. 7, pp. 7407-7427, 2015.

[53] J. Kwac, J. Flora, and R. Rajagopal, "Household energy consumption segmentation using hourly data," IEEE Trans. Smart Grid, vol. 5, no. 1, pp. 420-430, 2014.

[54] S. Haben, C. Singleton, and P. Grindrod, "Analysis and clustering of residential customers energy behavioral demand using smart meter data," IEEE Trans. Smart Grid, vol. 7, no. 1, pp. 136-144, 2016.

[55] Y. Wang, Q. Chen, C. Kang, and Q. Xia, "Clustering of Electricity Consumption Behavior Dynamics Toward Big Data Applications," IEEE Trans. Smart Grid, vol. 7, no. 5, pp. 24372447, 2016.

[56] E. McKenna, I. Richardson, and M. Thomson, "Smart meter data: Balancing consumer privacy concerns with legitimate applications," Energy Policy, vol. 41, pp. 807-814, 2012. 